\title{
Effective Treatment of Advanced Colorectal Cancer by Rapamycin and 5-FU/Oxaliplatin Monitored by TIMP-1
}

\author{
Markus Wagner • Vincent Roh • Michael Strehlen • Alexander Laemmle • \\ Deborah Stroka $\cdot$ Bernhard Egger $\cdot$ Markus Trochsler $\cdot$ Kelly K. Hunt • \\ Daniel Candinas $\cdot$ Stephan A. Vorburger
}

Received: 25 May 2009 /Accepted: 3 June 2009 / Published online: 30 June 2009

(C) 2009 The Society for Surgery of the Alimentary Tract

\begin{abstract}
Aim The mTOR-inhibitor rapamycin has shown antitumor activity in various tumors. Bedside observations have suggested that rapamycin may be effective as a treatment for colorectal carcinomatosis.

Methods We established an orthotopic syngenic model by transplanting CT26 peritoneal tumors in Balb/C mice and an orthotopic xenograft model by transplanting SW620 peritoneal tumors in nu/nu mice. Expression levels of tissue inhibitor of matrix-metalloproteinases 1 (TIMP-1) in the tumor and serum was determined by enzyme-linked immunosorbent assay.

Results Rapamycin significantly suppressed growth of syngenic and xenografted peritoneal tumors. The effect was similar with intraperitoneal or oral rapamycin administration. Tumor suppression was further enhanced when rapamycin was combined with 5-fluorouracil and/or oxaliplatin. The combination treatment showed no acute toxicity. TIMP-1 serum levels correlated well $(\mathrm{CC}=0.75 ; P<0.01)$ with rapamycin treatment.

Conclusions Rapamycin suppressed advanced stage colorectal cancer, even with oral administration. Combining rapamycin with current chemotherapy regimens significantly increased antitumor efficacy without apparent toxicity. The treatment efficacy correlated with serum TIMP-1 levels, suggesting its potential as a surrogate marker in future clinical trials.
\end{abstract}

Keywords mTOR inhibitor - Rapamycin · 5-FU .

Oxaliplatin · TIMP-1 $\cdot$ Colorectal cancer

\section{Introduction}

About $25 \%$ of patients with symptoms from colorectal cancer show peritoneal seeding of tumor cells (peritoneal carcinomatosis). ${ }^{1}$ The prognosis for patients with peritoneal

Paper presented at Digestive Disease Week, May 2009, Chicago, USA

M. Wagner · V. Roh · M. Strehlen · A. Laemmle $\cdot$ D. Stroka $\cdot$

B. Egger $\cdot$ M. Trochsler $\cdot$ D. Candinas $\cdot$ S. A. Vorburger $(\bowtie)$

Department of Visceral and Transplantation Surgery and

Department of Clinical Research, Inselspital,

University Hospital Bern and University of Bern,

CH-3010 Bern, Switzerland

e-mail: stephan.voburger@insel.ch

K. K. Hunt

Department of Surgical Oncology, University of Texas,

M.D. Anderson Cancer Center,

Houston, TX, USA carcinomatosis is somber. The estimated 5-year survival is less than $10 \%,{ }^{2}$ despite improved tumor responses to combinations of basic chemotherapy (5-fluorouracil [5$\mathrm{FU}]+$ leucovorin) with either Irinotecan or oxaliplatin (FOLFOX) and more recently with bevacizumab. To significantly improve survival for these patients, novel treatment strategies are needed.

Rapamycin is a bacterial macrolide that forms a complex with the FK506-binding protein (FKBP-12) and inactivates the mammalian target of rapamycin (mTOR). mTOR is activated through the phosphoinositide 3 kinase (PI3K), protein kinase $\mathrm{B} /$ rat sarcoma (Akt/Ras) pathway and leads to protein synthesis and cell proliferation. Accordingly, aberrant activation of mTOR has been observed in more than $30 \%$ of epithelial cancers (reviewed in ${ }^{3,4}$ ). Nearly $40 \%$ of carcinomas of the colorectum exhibit either partial or complete positive staining for a downstream factor of mTOR, phospho-S6K. This suggests that they are rapamycin-sensitive lesions. ${ }^{5}$ However, the antitumor activity of rapamycin is two-pronged; it has direct antiproliferative effects and also inhibits tumor-angiogenesis. ${ }^{6,7}$ 
Seeliger et al. reported that rapamycin increased antitumor activity by counteracting 5-FU-induced expression of angiogenetic 2-deoxy-ribose (dRib) in a mouse colorectal tumor model. ${ }^{8}$ Other groups have reported various synergistic effects of rapamycin with experimental agents, including radiation therapy and the DNA-damaging agents, cisplatin, oxaliplatin, and doxorubicin. ${ }^{9-14}$

Several synthetic rapamycin homologues have been tested in clinical trials for brain tumors, renal cell carcinoma, gynecologic cancer, lung cancer, and sarcomas (reviewed in Figlin ${ }^{15}$ ). ${ }^{16-19}$ However, early clinical trials have been hampered by difficulties in demonstrating biologic activity of the tested compound in advanced disease.

In order to set the stage for rapamycin therapy in advanced colorectal cancer, it would be desirable to identify a suitable surrogate marker to monitor antitumor activity. The tissue inhibitor of matrix metalloproteinases 1 (TIMP1) has been shown to correlate with disease stage and tumorigenicity of colorectal cancer ${ }^{20,21}$ (and reviewed $\mathrm{in}^{22}$ ). TIMP-1 shares homology with its three other family members, and all display a robust sensitivity to changes in $\mathrm{pH}$, temperature, and denaturing conditions due to their disulphide bonds. ${ }^{23}$ The N-terminal domain displays inhibitory activity against matrix metalloproteinases (MMPs) and contains the consensus sequence VIRAK. ${ }^{24}$ TIMP-1 is expressed and secreted by many cells of most tissues. The TIMP-1 protein includes a signal peptide that directs its secretion into the extracellular space. One of the main functions of TIMP-1 is the inhibition of MMPs. This activity is involved in the tissue remodeling observed in inflammation, wound healing, and cancer invasion. ${ }^{25,26}$ TIMP-1 binding to the cell surface activates the PI3K signaling pathway, which leads to cell proliferation. ${ }^{27,28}$ Conversely, inhibition of the PI3K pathway through PTEN (a tumor suppressor that prevents phosphorylation of $\mathrm{Akt}$ ) resulted in down-regulation of epidermal growth factorinduced TIMP-1 expression. ${ }^{29}$ Because it has also been reported that rapamycin caused down-regulation of TIMP-1 expression in experimental transplant rejection, we were interested in whether serum TIMP-1 expression levels might serve as a surrogate marker for the efficacy of rapamycin-based anticancer regimens. ${ }^{30,31}$

\section{Material and Methods}

\section{Cell Lines and Chemicals}

SW620 human colonic carcinoma cells and CT26 mouse colon carcinoma cells (derived from a murine Balb/c colon carcinoma) were obtained from the American Type Culture Collection (Rockville, MD, USA). We obtained 3-(4,5- methylthiazol-2-yl)-2,5-diphenyltetrazolium bromide (MTT), tetrazolium salt, and all other chemicals and reagents from Sigma Chemical Corp. (Buchs, Switzerland). Immunohistochemistry was performed with rabbit antiTIMP-1 (H-150; Santa Cruz Biotechnology; LabForce AG, Nunningen, Switzerland). The substrate solution for enzyme-linked immunosorbent assay (ELISA; ImmunoPure TMB Substrate Kit) were from Pierce (Perbio Science, Lausanne, Switzerland). The DuoSet kit (ELISA Development System) was used with mouse (DY980) and human anti-TIMP-1 (DY970) antibodies from R\&D Systems Inc. (Minneapolis, USA). Rapamycin (Rapamune ${ }^{\circledR}$ ) was from Wyeth Pharmaceuticals (Zug, Switzerland), 5-FU was from Roche Pharma (Reinach, Switzerland), and oxaliplatin was from Sanofi-Synthélabo (Meyrin, Switzerland).

\section{Cell Cytotoxicity Assay}

Cell cytotoxicity was determined as described previously ${ }^{32}$ by colorimetric assays (MTT dye reduction assay) performed with the Ultra-microplate reader EL808 (Bio-Tek instruments Inc, Winooski, USA). Cells were plated in triplicate at a density of $1 \times 10^{4}$ in 96-well plates in $0.2 \mathrm{ml}$ normal growth medium and incubated at $37^{\circ} \mathrm{C}$, with $5 \%$ $\mathrm{CO}_{2}$. All assays were repeated at least three times.

Orthotopic, Syngenic, and Xenograft Animal Models

Four- to 6-week-old female, 20-25 g Balb/c OlaHsd mice and athymic Nude-Foxn $1^{\text {nu }}$ mice (Harlan Netherlands B.V., Horst, Netherlands) were housed in individual ventilated cages under sterile conditions according to the Swiss guidelines for the care and use of laboratory animals. Sterile food and water were provided ad libitum. Animal procedures were approved by the regional authorities according to Swiss animal-care regulations. To create an orthotopic model of peritoneal carcinomatosis, CT26 or SW620 cells were injected at a density of $5 \times 10^{5}$ cells $/ 50 \mu \mathrm{l}$ into the peritoneal cavity of BALB/c (syngenic model) or nude mice (xenograft model), respectively. Preliminary analysis of stably transplanted CT26 cells by bioluminescence imaging showed that $100 \%$ of mice developed tumors, and the localization of tumors was reminiscent of peritoneal carcinomatosis in humans. Five days after tumorcell inoculation, once peritoneal carcinomatosis was established, treatment was initiated. Mice were followed daily and killed by $\mathrm{CO}_{2}$ euthanasia when ascites or tumor development interfered with the well-being of the animals or at the end of experiments. Tumors from the peritoneal cavity were carefully excised under a surgical microscope (magnification $\times 4$ ). The total excised tumor was weighed, and the ascites volume was measured. Specimens from the tumor, colon, liver, and lungs were embedded in paraffin. 


\section{Antitumor Agents}

Rapamycin was diluted in water and administered orally or intraperitoneally (i.p.) at 0.15 or $1.5 \mathrm{mg} / \mathrm{kg}$ every 2 days, respectively. In mice, a dosage of $1.5 \mathrm{mg} \mathrm{kg}^{-1}$ day $^{-1}$ has been shown to produce steady-state rapamycin serum levels in a range similar to that used on a long-term basis in organ transplantation to prevent allograft rejection. ${ }^{6}$ 5-FU was diluted in $0.9 \%$ saline and administered i.p. at $100 \mathrm{mg} / \mathrm{kg}$ on days 7 and 14. Thereafter, $5-\mathrm{FU}$ was given at $50 \mathrm{mg} / \mathrm{kg}$ every 7 days to the end of the experiment, as described previously. ${ }^{6}$ It was reported that $100 \mathrm{mg} / \mathrm{kg} 5$-FU was the maximum tolerated dose in mice. ${ }^{33}$ Oxaliplatin (Eloxatin ${ }^{\circledR}$ ) was prepared according to the description of the manufacturer and administered i.p. at $5 \mathrm{mg} / \mathrm{kg} / \mathrm{d}$ for 5 days. For combination treatment experiments with rapamycin +5 FU/Oxal, half of the above dose of Oxaliplatin was used. Cyclosporine A was given orally by gavage at a dose of $15 \mathrm{mg} / \mathrm{kg}$ every 2 days as described previously.

\section{Determination of TIMP-1}

Cell lysates, tissue lysates, and tail vein serum samples spun at $1,500 \times g$ were analyzed with enzyme-linked immunosorbent assay for TIMP-1 quantitation according to manufacturer specifications (DuoSet, ELISA Development System, mouse TIMP-1 or human TIMP-1; R\&D Systems Inc., USA). Wells were incubated for $20 \mathrm{~min}$ in substrate solution (ImmunoPure TMB Substrate Kit, Pierce, USA). The optical density of each well was determined immediately with a microplate reader (EL808, Microplate Reader, Bio-Tek Instruments Inc., USA) at a wavelength of $450 \mathrm{~nm}$ (wavelength correction set to $562 \mathrm{~nm}$ ). A standard curve was created by reducing the data to a fourparameter logistic (4-PL) curve fit with KC4-Software (Kineticalc for Windows; version \# 3.03, Rev. \# 4, Bio-Tek Instruments Inc., USA). Comparison of the optical density of each well to the standard curve provided a relative measurement of protein concentration. Measurements were performed in triplicate.

Immunohistochemistry

Tumor tissue samples were fixed in 4\% formalin, processed, and embedded in paraffin. Paraffin embedded tissue samples were sliced into $5 \mu \mathrm{m}$ sections and processed according to the manufacturer's protocol (Vectastain ABC Elite Kit, Vector Laboratories, Burlingame, CA, USA). For antigen retrieval, samples were digested with Proteinase $\mathrm{K}$ at a concentration of $5 \mu \mathrm{g} / \mathrm{ml}$ at $37^{\circ} \mathrm{C}$ for $20 \mathrm{~min}$. Rabbit polyclonal TIMP-1 antibodies (H-150) were added at a final concentration of $1 \mu \mathrm{g} / \mathrm{ml}$, and sections were incubated overnight at $4^{\circ} \mathrm{C}$. Sections were developed with $3,3^{\prime}-$ diaminobenzidine (SigmaFast 3,3'-diaminobenzidine tablet sets, Sigma-Aldrich, USA) substrate for a maximum of $10 \mathrm{~min}$.

\section{Statistics}

Statistical software NCSS (Kaysville, UT, USA) was used to analyze the data. One-way analysis of variance (ANOVA) and $t$ tests were used where appropriate. The significance level was set at 0.05. Whiskers (10th and 90th), box margins (25th and 75th), and the midline of box plots (50th) depict the percentiles of the respective variable. Linear regression modeling was used for the estimation of correlations. The regression coefficient and $R^{2}$ were calculated. The Spearman rank correlation coefficient was used to estimate confidence levels and probabilities.

\section{Results}

Rapamycin Inhibited Growth of Peritoneal Carcinomatosis

A dose escalation of rapamycin on CT26/SW620 cells in vitro showed direct cytotoxicity (determined by MTT assays) only at very high concentrations (>100 ng/ml; data not shown). In vivo, rapamycin administered orally (gavage) or intraperitoneally (i.p.) caused significant suppression of peritoneal tumor growth in Balb/c mice (syngenic model with CT26 cells; Fig. 1a, b). The antitumor efficacy of rapamycin at "pharmacological doses" (hd Rap) and at one tenth of that concentration (ld Rap) was similar to the tumor suppressive activity of 5FU or oxaliplatin (Fig. 1a). In contrast, treatment with the immunosuppressive agent cyclosporine A, another immunosuppressive drug used to inhibit transplant rejection, did not decrease tumor growth (Fig. 1b). Mice in the rapamycin-treated group showed very low amounts of ascites, but mice in the cyclosporine A and control groups showed marked formation of malignant ascites (Fig. 1c).

Combination of Rapamycin with 5-FU- and/or OxaliplatinEnhanced Growth Inhibition of Syngenic Tumors with no Apparent Toxicity

Rapamycin combined with either 5-FU or oxaliplatin showed superior tumor suppression compared to rapamycin as a single agent therapy (Fig. 2a, b). No acute or chronic toxicity was noted, but two mice of the oxaliplatin alone group showed subcutaneous necrosis at the site of injection, likely due to an inaccurate injection. Body weight was maintained in balance over most of the observation period. However, in control treated animals, weight increased in proportion to apparent ascites and tumor load. This finally 


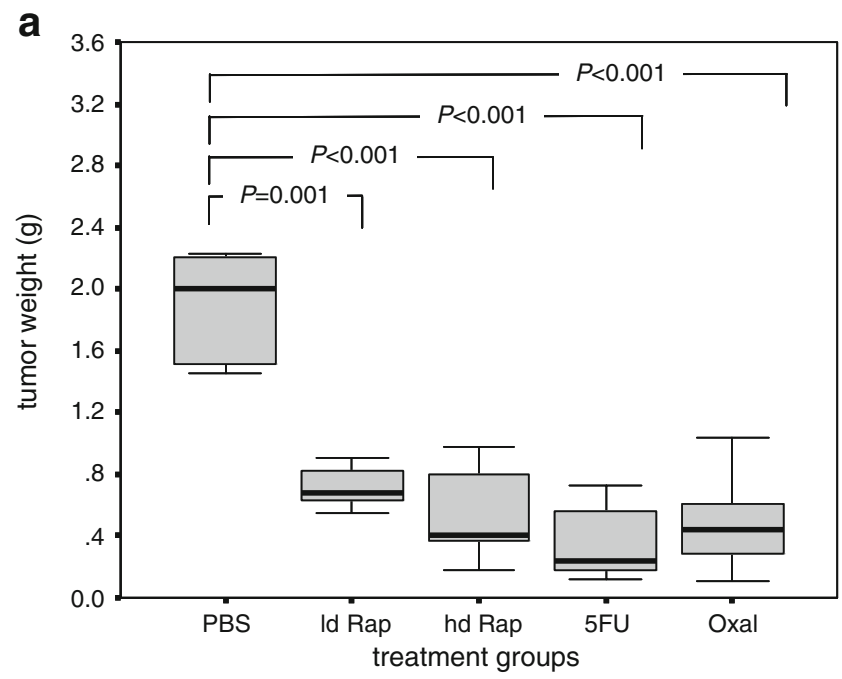

b

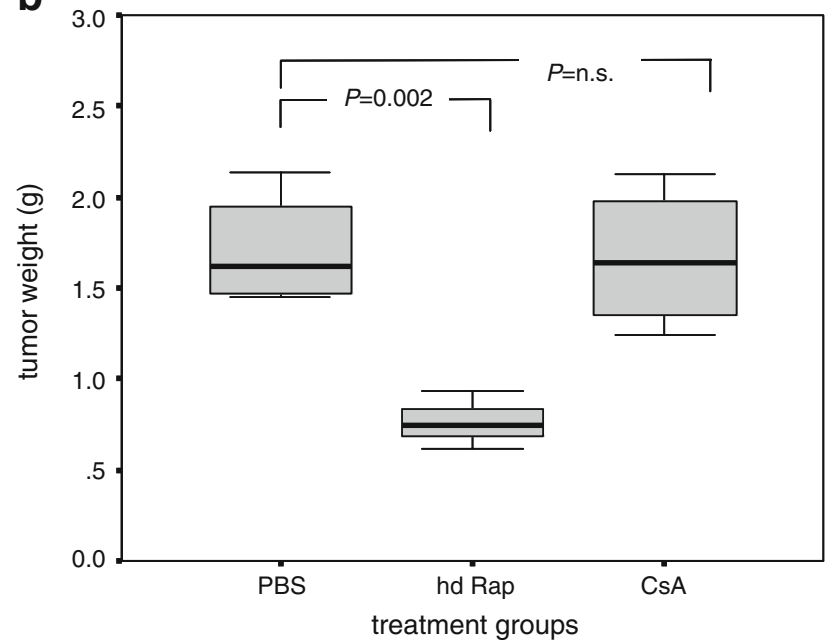

C

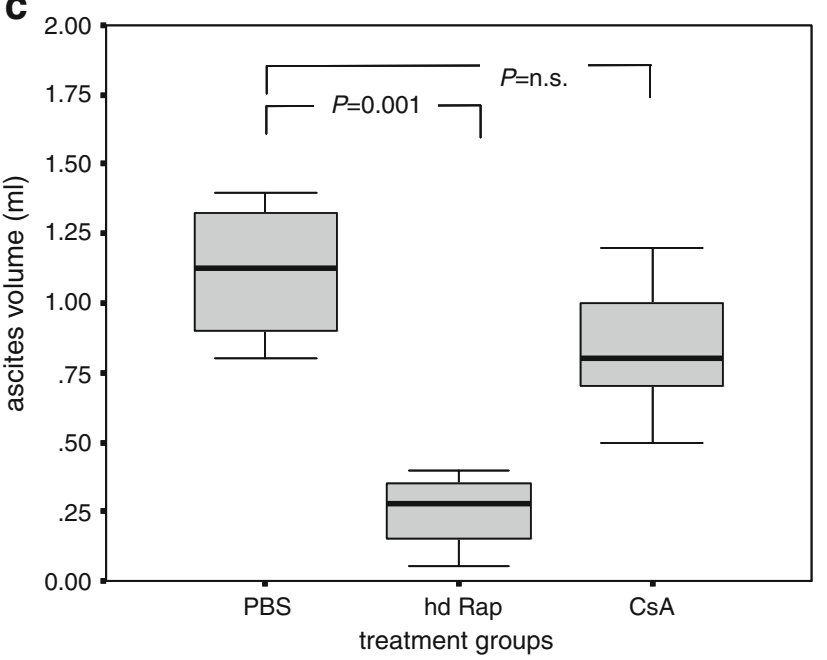

led to early killing of the animals because interference with well-being was noted (Fig. 2c). H\&E staining of paraffinembedded liver samples did not reveal ultrastructural changes that indicated acute or chronic hepatic toxicity (analysis by an independent pathologist; Fig. 2d).
Figure 1 a Intraperitoneal administration of rapamycin, 5-FU, or oxaliplatin resulted in tumor suppression. Box plots represent tumor weights at the end of the experiment. Mouse colon carcinoma cells (CT26; $5 \times 10^{5}$ cells) were injected into the peritoneal cavity of syngenic Balb/c mice. Twenty-two days after intraperitoneal injection of CT26 cells and 17 days after treatment initiation, mice were killed. Treatment groups were: $P B S$; ld Rap low-dose rapamycin, $0.15 \mathrm{mg} / \mathrm{kg}$ every 2 days; $h d$ Rap high-dose rapamycin, $1.5 \mathrm{mg} / \mathrm{kg}$ every 2 days; $5-F U 100 \mathrm{mg} / \mathrm{kg}$ every 7 days for the first 2 weeks, then $50 \mathrm{mg} / \mathrm{kg}$ every 7 days until the end of the experiment; and oxaliplatin $5 \mathrm{mg} \mathrm{kg}^{-1}$ day $^{-1}$ for 5 days). The group size was $n=8$. Significant tumor growth suppression compared to controls was noted in the various treatment groups ( $t$ test). b Tumor growth was significantly inhibited by orally administered rapamycin but not by the immunosuppressive agent cyclosporine A. Box-plots represent the weight of peritoneal tumors. The tumor model is the same as in a. Treatment groups were: $P B S$; hd Rap high dose rapamycin, $1.5 \mathrm{mg} / \mathrm{kg}$ every 2 days; cyclosporine A, $15 \mathrm{mg} / \mathrm{kg}$ every 2 days. The group size was $n=8$. c Significantly smaller tumor size and less ascites formation were noted in hd Rap compared to controls but not in the CsA group ( $t$ test).

Rapamycin Treatment Alone and in Combination Inhibited Tumor Growth of Human Xenograft Peritoneal Carcinomatosis

Both rapamycin and "FOLFOX" (5-FU+oxaliplatin) treatments caused significant suppression of the peritoneal tumor growth induced by human colorectal SW620 cancer in nude mice. The antitumor effect was enhanced by a combination of rapamycin with 5-FU+oxaliplatin (Fig. 3). At low doses of rapamycin (one tenth of the "standard" dose), tumor suppression was enhanced compared to 5-FU+oxaliplatin treatment alone. The effect was further enhanced when rapamycin was given at a high dose. Again, no acute or chronic toxicity was observed as confirmed by histological analysis of liver tissue and body weight curves.

TIMP-1 Was Down-Regulated by Rapamycin Treatment in Cancer Cells and Tumors

CT26 or SW620 cell lysates showed a dose-dependent decrease in TIMP-1 protein levels after addition of rapamycin to the culture media (Fig. 4a; CT26). Hence, low to medium-high doses of rapamycin down-regulated TIMP-1 expression without apparent toxic effects, as shown by immunohistochemistry (Fig 4b) and western blots (not shown). Compared to phosphate-buffered saline (PBS)-treated mice, the combination of 5-FU and oxaliplatin also lowered intratumoral TIMP-1 expression but significantly less than rapamycin treatment.

\section{Serum Levels of TIMP-1 Correlated with Antitumor Activity of Rapamycin}

The expression levels of TIMP-1 in serum samples from mice with syngenic CT26 tumors correlated well with tumor weight $(\mathrm{CC}=0.76$; Fig. $4 \mathrm{c})$. The correlation was 


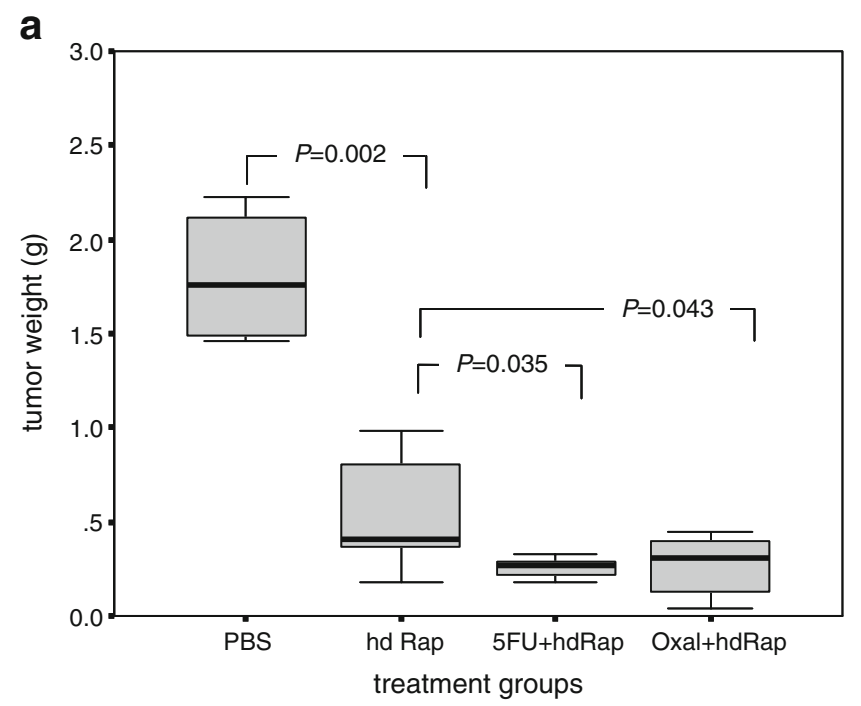

b
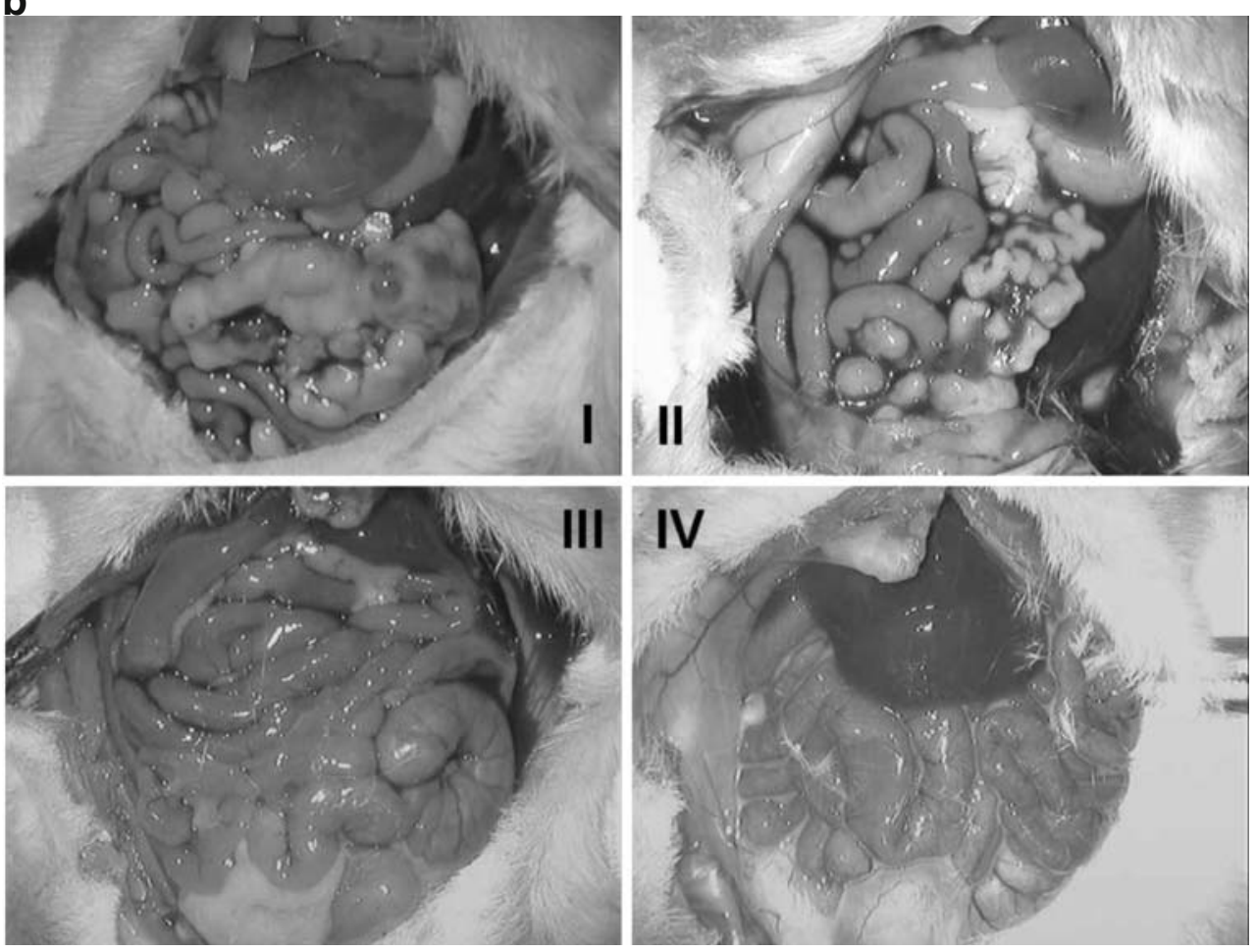

Figure 2 a, b Rapamycin combined with 5-FU or oxaliplatin inhibited tumor growth more efficiently than rapamycin alone. Boxplots represent weight of peritoneal tumors (a). Animals ( $n=8 /$ group) with established syngenic, orthotopic tumors ( 5 days after injection of $5 \times 10^{5}$ CT26 cells) were treated with rapamycin (hd Rap, $1.5 \mathrm{mg} / \mathrm{kg}$ every 2 days $)$ in combination with either 5 -FU $(100 \mathrm{mg} / \mathrm{kg}$ every 7 days for the first 2 weeks, then $50 \mathrm{mg} / \mathrm{kg}$ every 7 days) or oxaliplatin (5 mg kg${ }^{-1}$ day $^{-1}$ for 5 days). All compounds were administered i.p. Mice were killed 22 days after tumor inoculation. Rapamycin combined with 5-FU or oxaliplatin inhibited tumor growth more effectively than rapamycin treatment alone ( $t$ test). b Picture of mice described in a: I PBS; II hd Rap; III 5-FU + hd Rap; IV Oxal + hd Rap. Tumor load was significantly reduced by rapamycin alone and in combination treatments of rapamycin with 5-FU or oxaliplatin. c Treatment with rapamycin alone or in combination did not influence

body weight ( $n=8 /$ group). Graphs depict body weight of mice from a measured every second day after tumor cell inoculation. Mice were treated with PBS, rapamycin, or a combination of rapamycin and 5FU or oxaliplatin as stated above (a). The body weight of control mice (PBS), with tumor loads of up to $2.5 \mathrm{~g}$ and ascites formations, was significantly different from that of the most effective treatment group, with no macroscopic tumor and no ascites (hd Rap $+5-\mathrm{FU} ; P=0.04$ ). For the other groups, body weight tended to be lower than that of control animals. No significant intergroup differences were noted between treatments (one-way ANOVA). d Treatment with rapamycin alone or in combination did not alter the ultrastructure of the liver. H\&E staining of liver samples ( $n=8 /$ group) displayed no change in the ultrastructure of the liver parenchyma after 17 days of treatment with PBS, oxaliplatin, or a combination of rapamycin with oxaliplatin and 5-FU. 

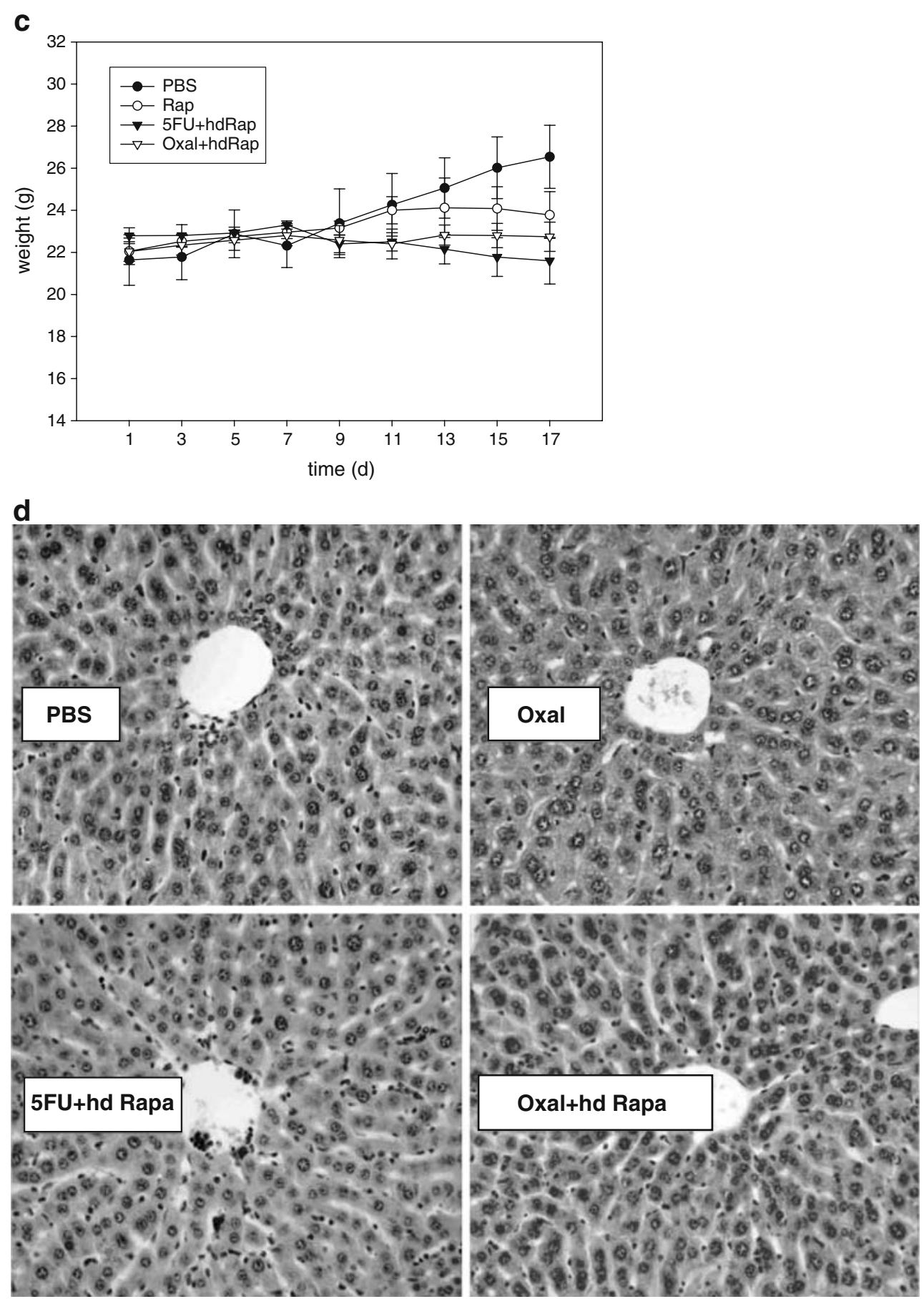

Figure 2 (continued).

more pronounced in mice treated with the combination of rapamycin and 5-FU/Oxal compared to mice treated without rapamycin, where no significant correlation to tumor weight was observed. This suggested that both TIMP-1 secretion from the tumoral tissue and the secretion from healthy tissues were affected by direct TIMP-1 suppression and indirect suppression by mTOR inhibition (the biological activity of rapamycin), respectively. Peritu- moral tissue is likely to contribute to TIMP-1 serum levels. However, the fact that human TIMP-1 serum levels correlated well (correlation coefficient $=0.75$ ) with tumor weight in mice carrying a human SW620 xenograft tumor suggested that peritumoral TIMP-1 expression due to inflammation or a reaction to increased tissue levels of MMPs was not the dominant source of the TIMP-1 correlation. 


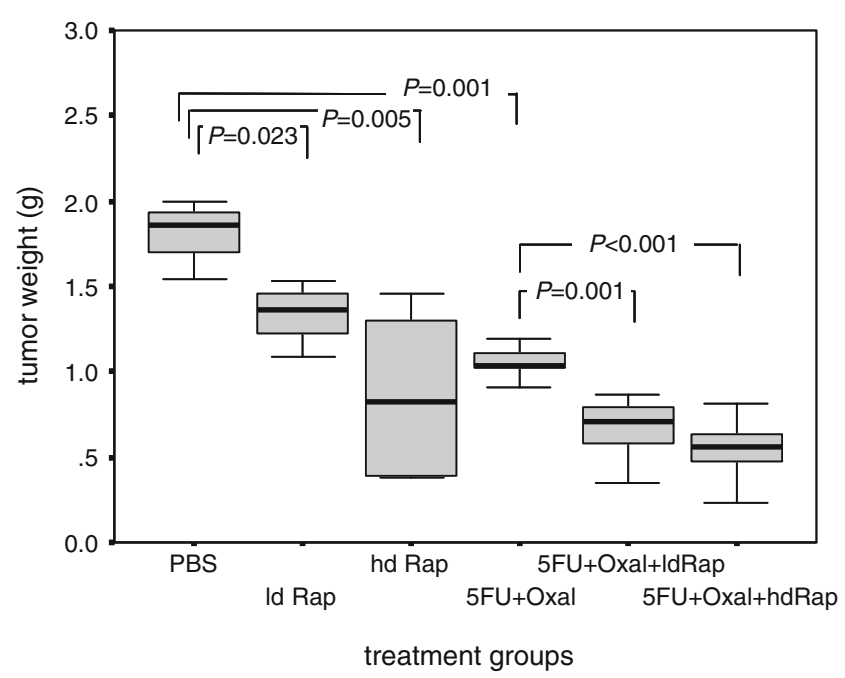

Figure 3 Growth of peritoneal xenograft tumors was significantly suppressed by rapamycin alone or in combination with 5-FU +oxaliplatin. Box-blots represent tumor weight in different treatment groups. SW620 cells $\left(5 \times 10^{5}\right)$ were injected intraperitoneally in athymic nude mice. Treatment was initiated after 7 days for a total of 35 days, when mice were killed. Treatment groups $(n=8)$ were: Controls (PBS); low-dose rapamycin (ld Rap, $0.15 \mathrm{mg} / \mathrm{kg}$ every 2 days) per gavage; high-dose rapamycin (hd Rap, $1.5 \mathrm{mg} / \mathrm{kg}$ every 2 days) per gavage; 5 -FU+oxaliplatin $\left(5-F U, 100 \mathrm{mg} \mathrm{kg}^{-1}\right.$ week $^{-1}$, i.p. for the first 2 weeks, thereafter $50 \mathrm{mg} / \mathrm{kg}$ every week + Oxal: $5 \mathrm{mg} \mathrm{kg}{ }^{-1} \mathrm{day}^{-1}$, i.p. for 5 days); and a combination of rapamycin with 5-FU+Oxal (at above doses). Significant suppression of tumor growth compared to controls was noted following oral administration of rapamycin (ld Rap and hd Rap). Likewise, a combination treatment of 5-FU + oxaliplatin significantly inhibited tumor growth. The antitumor effect was synergistically enhanced by combination of rapamycin with 5-FU+oxaliplatin compared to 5-FU+Oxal alone $(P$ values between groups: $t$ test; intergroup differences: one-way ANOVA).

\section{Discussion}

Our results corroborate preclinical and early clinical findings from various tumors that the mTOR-inhibitor rapamycin has antitumor efficacy. Our motivation to undertake this study was the observation that a 62-yearold patient, immunosuppressed due to liver transplantation for 2 years, was treated for adenocarcinoma of the colon with peritoneal carcinomatosis by local resection and adjuvant chemotherapy (FOLFOX). At that time, immunosuppression was changed to rapamycin. Two years later, he experienced an incisional hernia that required repair. At that time, peritoneal carcinomatosis had resolved but for one small lesion. Now, 6 years after the initial diagnosis, the patient is alive with no manifestations of peritoneal carcinomatosis (personal observation).

In our syngenic and xenograft orthotopic mouse models for peritoneal carcinomatosis, rapamycin treatment significantly inhibited tumor growth. The pronounced antitumor effect was consistently observed in our experiments. This study extends other work that showed rapamycin activity against colorectal liver metastases. ${ }^{6,8,34}$ We demonstrated that this anticancer effect occurs even in more advanced, late-stage disease and with either intraperitoneal application or oral administration of rapamycin. This is relevant because rapamycin (Rapamune ${ }^{\circledR}$ ) is a highly lipophilic solution given orally to transplanted patients. In previous studies on colorectal cancer, solvents (dimethylsulfoxide or ethanol) that are cytotoxic were used for intraperitoneal rapamycin injections. ${ }^{6}$ Here, we emulsified rapamycin in distilled water and then applied this emulsion intraperitoneally and orally, in order to minimize direct cytotoxic effects. The route of application did not influence the antitumor activity of rapamycin.

In order to mimic treatment regimens in potential future clinical trials (e.g., FOLFOX plus rapamycin), we combined rapamycin treatment with 5-FU and/or oxaliplatin. The combination therapy showed improved efficacy for colorectal carcinoma without increasing toxicity. In addition, when rapamycin was combined with half the recommended dosing of 5-FU/Oxaliplatin, tumor suppression was equally effective. Thus, systemic toxicity and side effects can be reduced with this chemotherapy in the future. ${ }^{35} \mathrm{~A}$ recent study showed that a combination of rapamycin with irinotecan had pronounced antitumor effects on colorectal xenografts, dependent on the hypoxic state of cells. ${ }^{34}$ In histologic evaluation of tumors, we did not find necrotic patterns typical of oxygen dependency.

Early studies in transplant rejection showed that rapamycin down-regulated TIMP-1, a factor overexpressed in patients with advanced colorectal cancer and associated with advanced tumor stages, poor outcome, and chemoresistance. ${ }^{21,22,36}$ In this study, treatment with rapamycin caused nearly complete disappearance of TIMP-1 in tumor tissue samples. Because TIMP-1 has broad tumorpromoting activity (pro-angiogenesis, anti-apoptosis; promotion of cell growth and proliferation), one could speculate that its down-regulation by rapamycin could be another mechanism through which rapamycin mediates its antitumor effects. ${ }^{37,38}$ We found that TIMP-1 expression in the tissue and the serum correlated well with the antitumor effect of rapamycin. A high rapamycin dose yielded lower TIMP-1 than a low rapamycin dose for similar tumor sizes. This suggested that TIMP-1 serum levels mirrored both antitumor activity and biological activity. In addition, we found that human TIMP-1 serum levels in mice carrying human SW620 tumors correlated well with tumor weight and that TIMP-1 levels were not influenced by treatment with the immunosuppressive agent cyclosporine A. This provided corroborating evidence that serum levels of TIMP-1 reflected primarily tumor load and proliferation rather than a reaction of the peritumoral tissue. ${ }^{39}$ 
Figure 4 a Rapamycin downregulated TIMP-1 expression. Forty-eight hours after cellcultures were treated with PBS, $5 \mathrm{ng} / \mathrm{ml}$, or $50 \mathrm{ng} / \mathrm{ml}$ rapamycin, the whole cell lysates of CT26 cells were analyzed for TIMP-1 expression by ELISA (normalized to $1 \mu \mathrm{g}$ of total protein). Compared to PBS-treated cells, a significant down-regulation of TIMP-1 protein levels was observed in the cells treated with high-dose rapamycin $(P<0.001$; $t$ test). b Intratumoral TIMP-1 was strongly down-regulated after rapamycin treatment. Hematoxylin-eosin staining of peritoneal CT26 syngenic tumor from experiment in a $(A)$. Sections were subjected to immunohistochemistry for TIMP-1 (brown staining) and counterstained for nuclei (blue; $B-D$ ). Cytoplasmic and extracellular expression of TIMP-1 was strongly reduced after rapamycin treatment $(D)$ compared to controls $(B)$. 5-FU+Oxal therapy (C) led to a weak downregulation of TIMP-1 in the tumors. c TIMP-1 serum levels correlated with tumor weight. Whole blood taken from the tail vein of CT26 tumor-bearing Balb/c mice at the time of killing was spun down and the serum analyzed for TIMP-1 expression by ELISA. Linear regression analysis showed that tumor weight was correlated with TIMP-1 expression in mice treated with PBS, FU/Oxal alone, and in combination with low- or high-dose rapamycin. Data are representative of one experimental run. A very good positive correlation between tumor weights and TIMP-1 serum levels was calculated (correlation coefficient $=0.77$ (Spearman rank); $P<0.005)$.

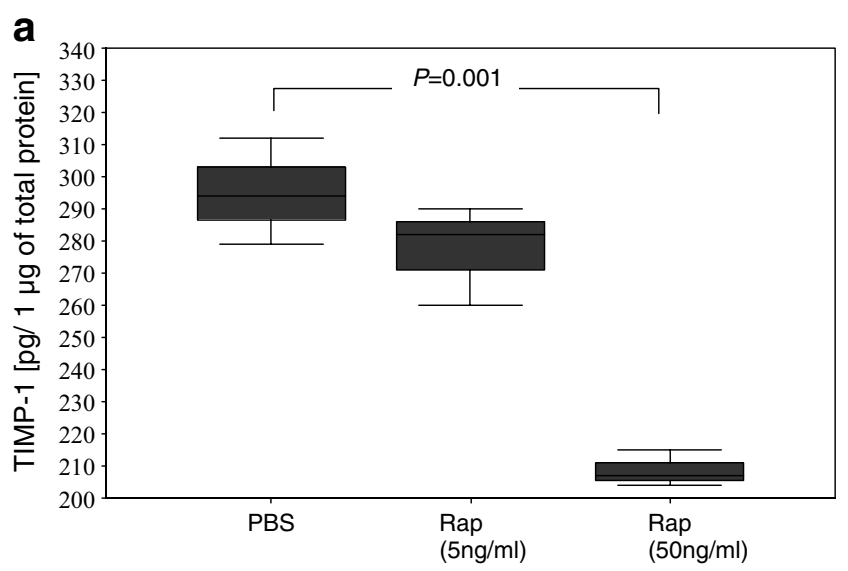

b
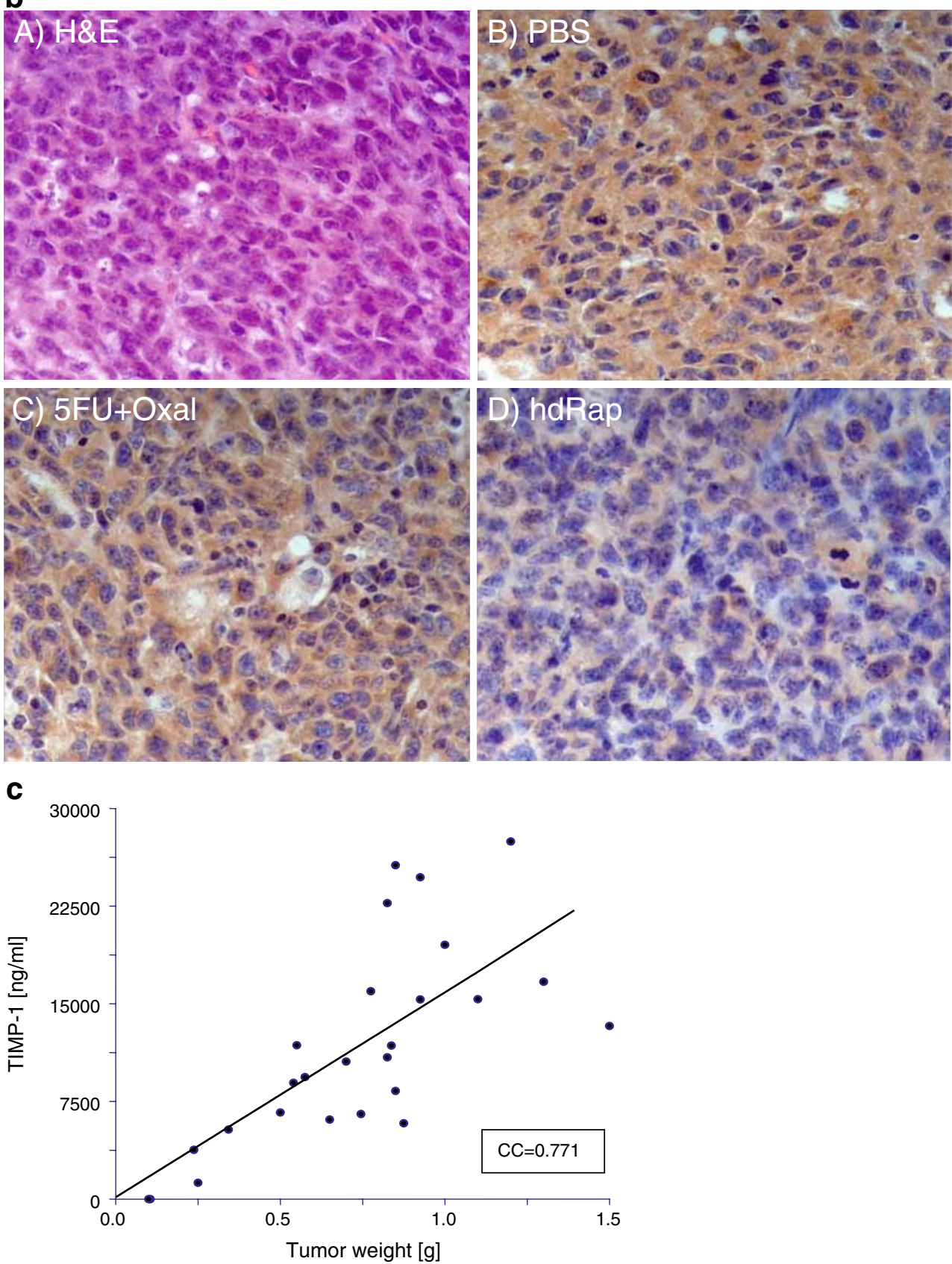


\section{Conclusion}

The combination of rapamycin with 5-FU and oxaliplatin had strong synergistic effects against late-stage colorectal cancer even at reduced dosing. Hence, our findings suggest that rapamycin combined with current state-of-the-art chemotherapy should enter phase I/II clinical trials as a treatment for late-stage colorectal carcinoma. TIMP-1 serum levels can easily be monitored as a surrogate marker to measure antitumor activity in patients with peritoneal carcinomatosis.

Acknowledgment We would like to thank Cynthia Fuhrer (University of Bern) for her help with immunohistochemistry.

Grant support This work was supported by the 3R Research Foundation Switzerland (no 94/04); Swiss National Foundation (SNF 3100A0-104023); Oncosuisse (OCS 01431-08-2003) (SAV).

\section{References}

1. Jemal A, Murray T, Samuels A, Ghafoor A, Ward E, Thun MJ. Cancer statistics, 2003. CA Cancer J Clin 2003;53:5-26.

2. Gill S, Thomas RR, Goldberg RM. Review article: colorectal cancer chemotherapy. Aliment Pharmacol Ther 2003;18:683-692.

3. Chan S. Targeting the mammalian target of rapamycin (mTOR): a new approach to treating cancer. Br J Cancer 2004;91:1420-1424.

4. Law BK. Rapamycin: an anti-cancer immunosuppressant? Crit Rev Oncol Hematol 2005;56:47-60.

5. Nozawa H, Watanabe T, Nagawa H. Phosphorylation of ribosomal p70 S6 kinase and rapamycin sensitivity in human colorectal cancer. Cancer Lett 2007;251:105-113.

6. Guba M, von Breitenbuch P, Steinbauer M, Koehl G, Flegel S, Hornung M, Bruns CJ, Zuelke C, Farkas S, Anthuber M, Jauch KW, Geissler EK. Rapamycin inhibits primary and metastatic tumor growth by antiangiogenesis: involvement of vascular endothelial growth factor. Nat Med 2002;8:128-135.

7. Guba M, Yezhelyev M, Eichhorn ME, Schmid G, Ischenko I, Papyan A, Graeb C, Seeliger H, Geissler EK, Jauch KW, Bruns CJ. Rapamycin induces tumor-specific thrombosis via tissue factor in the presence of VEGF. Blood 2005;105:4463-4469.

8. Seeliger H, Guba M, Koehl GE, Doenecke A, Steinbauer M, Bruns CJ, Wagner C, Frank E, Jauch KW, Geissler EK. Blockage of 2-deoxy-D-ribose-induced angiogenesis with rapamycin counteracts a thymidine phosphorylase-based escape mechanism available for colon cancer under 5-fluorouracil therapy. Clin Cancer Res 2004;10:1843-1852.

9. Eshleman JS, Carlson BL, Mladek AC, Kastner BD, Shide KL, Sarkaria JN. Inhibition of the mammalian target of rapamycin sensitizes U87 xenografts to fractionated radiation therapy. Cancer Res 2002;62:7291-7297.

10. Grunwald V, DeGraffenried L, Russel D, Friedrichs WE, Ray RB, Hidalgo M. Inhibitors of mTOR reverse doxorubicin resistance conferred by PTEN status in prostate cancer cells. Cancer Res 2002;62:6141-6145.

11. Shi Y, Frankel A, Radvanyi LG, Penn LZ, Miller RG, Mills GB. Rapamycin enhances apoptosis and increases sensitivity to cisplatin in vitro. Cancer Res 1995;55:1982-1988.

12. Zhang YJ, Tian XQ, Sun DF, Zhao SL, Xiong H, Fang JY. Combined inhibition of MEK and mTOR signaling inhibits initiation and progression of colorectal cancer. Cancer Invest 2009;27:273-285.

13. Cejka D, Preusser M, Fuereder T, Sieghart W, Werzowa J, Strommer S, Wacheck V. mTOR inhibition sensitizes gastric cancer to alkylating chemotherapy in vivo. Anticancer Res 2008;28:3801-3808.

14. Leelawat K, Narong S, Udomchaiprasertkul W, Leelawat S, Tungpradubkul $\mathrm{S}$. Inhibition of $\mathrm{PI} 3 \mathrm{~K}$ increases oxaliplatin sensitivity in cholangiocarcinoma cells. Cancer Cell Int 2009;9:3.

15. Figlin RA, Brown E, Armstrong AJ, Akerley W, Benson AB 3rd, Burstein HJ, Ettinger DS, Febbo PG, Fury MG, Hudes GR, Kies MS, Kwak EL, Morgan RJ Jr., Mortimer J, Reckamp K, Venook AP, Worden F, Yen Y. NCCN Task Force Report: mTOR inhibition in solid tumors. J Natl Compr Canc Netw 2008;6(Suppl 5):S1-S20. quiz S21-S22.

16. Amato RJ, Jac J, Giessinger S, Saxena S, Willis JP. A phase 2 study with a daily regimen of the oral mTOR inhibitor RAD001 (everolimus) in patients with metastatic clear cell renal cell cancer. Cancer 2009;115:2438-2446.

17. Hudes G, Carducci M, Tomczak P, Dutcher J, Figlin R, Kapoor A, Staroslawska E, Sosman J, McDermott D, Bodrogi I, Kovacevic Z, Lesovoy V, Schmidt-Wolf IG, Barbarash O, Gokmen E, O'Toole T, Lustgarten S, Moore L, Motzer RJ. Temsirolimus, interferon alfa, or both for advanced renal-cell carcinoma. N Engl J Med 2007;356:2271-2281.

18. Galanis E, Buckner JC, Maurer MJ, Kreisberg JI, Ballman K, Boni J, Peralba JM, Jenkins RB, Dakhil SR, Morton RF, Jaeckle KA, Scheithauer BW, Dancey J, Hidalgo M, Walsh DJ. Phase II trial of temsirolimus (CCI-779) in recurrent glioblastoma multiforme: a North Central Cancer Treatment Group Study. J Clin Oncol 2005;23:5294-5304.

19. Atkins MB, Hidalgo M, Stadler WM, Logan TF, Dutcher JP, Hudes GR, Park Y, Liou SH, Marshall B, Boni JP, Dukart G, Sherman ML. Randomized phase II study of multiple dose levels of CCI-779, a novel mammalian target of rapamycin kinase inhibitor, in patients with advanced refractory renal cell carcinoma. J Clin Oncol 2004;22:909-918.

20. Yukawa N, Yoshikawa T, Akaike M, Sugimasa Y, Takemiya S, Yanoma S, Imada T, Noguchi Y. Prognostic impact of tissue inhibitor of matrix metalloproteinase-1 in plasma of patients with colorectal cancer. Anticancer Res 2004;24:2101-2105.

21. Holten-Andersen MN, Nielsen HJ, Sorensen S, Jensen V, Brunner N, Christensen IJ. Tissue inhibitor of metalloproteinases-1 in the postoperative monitoring of colorectal cancer. Eur $\mathrm{J}$ Cancer 2006;42:1889-1896.

22. Sorensen NM, Schrohl AS, Jensen V, Christensen IJ, Nielsen HJ, Brunner N. Comparative studies of tissue inhibitor of metalloproteinases-1 in plasma, serum and tumour tissue extracts from patients with primary colorectal cancer. Scand J Gastroenterol 2008;43:186-191.

23. Stricklin GP, Welgus HG. Human skin fibroblast collagenase inhibitor. Purification and biochemical characterization. J Biol Chem 1983;258:12252-12258.

24. Avalos BR, Kaufman SE, Tomonaga M, Williams RE, Golde DW, Gasson JC. K562 cells produce and respond to human erythroidpotentiating activity. Blood 1988;71:1720-1725.

25. Hewitt RE, Brown KE, Corcoran M, Stetler-Stevenson WG. Increased expression of tissue inhibitor of metalloproteinases type 1 (TIMP-1) in a more tumourigenic colon cancer cell line. J Pathol 2000;192:455-459.

26. Chromek M, Tullus K, Lundahl J, Brauner A. Tissue inhibitor of metalloproteinase 1 activates normal human granulocytes, protects them from apoptosis, and blocks their transmigration during inflammation. Infect Immun 2004;72:82-88.

27. Chirco R, Liu XW, Jung KK, Kim HR. Novel functions of TIMPs in cell signaling. Cancer Metastasis Rev 2006;25:99-113. 
28. Luparello C, Avanzato G, Carella C, Pucci-Minafra I. Tissue inhibitor of metalloprotease (TIMP)-1 and proliferative behaviour of clonal breast cancer cells. Breast Cancer Res Treat 1999;54:235-244.

29. Soula-Rothhut M, Coissard C, Sartelet H, Boudot C, Bellon G, Martiny L, Rothhut B. The tumor suppressor PTEN inhibits EGFinduced TSP-1 and TIMP-1 expression in FTC-133 thyroid carcinoma cells. Exp Cell Res 2005;304:187-201.

30. Waller JR, Brook NR, Bicknell GR, Nicholson ML. Differential effects of modern immunosuppressive agents on the development of intimal hyperplasia. Transpl Int 2004;17:9-14.

31. Murphy G, Knauper V, Lee MH, Amour A, Worley JR, Hutton M, Atkinson S, Rapti M, Williamson R. Role of TIMPs (tissue inhibitors of metalloproteinases) in pericellular proteolysis: the specificity is in the detail. Biochem Soc Symp 2003;70:65-80.

32. Mosmann T. Rapid colorimetric assay for cellular growth and survival: application to proliferation and cytotoxicity assays. J Immunol Methods 1983;65:55-63.

33. Ishikawa T, Fukase Y, Yamamoto T, Sekiguchi F, Ishitsuka H. Antitumor activities of a novel fluoropyrimidine, N4-pentyloxycarbonyl-5'-deoxy-5-fluorocytidine (capecitabine). Biol Pharm Bull 1998;21(7):713-717.

34. Pencreach E, Guerin E, Nicolet C, Lelong-Rebel I, Voegeli AC, Oudet P, Larsen AK, Gaub MP, Guenot D. Marked activity of irinotecan and rapamycin combination toward colon cancer cells in vivo and in vitro is mediated through cooperative modulation of the mammalian target of rapamycin/hypoxia-inducible factor1alpha axis. Clin Cancer Res 2009;15:1297-1307.

35. Goldberg RM, Tabah-Fisch I, Bleiberg H, de Gramont A, Tournigand C, Andre T, Rothenberg ML, Green E, Sargent DJ. Pooled analysis of safety and efficacy of oxaliplatin plus fluorouracil/leucovorin administered bimonthly in elderly patients with colorectal cancer. J Clin Oncol 2006;24:4085-4091.

36. Holten-Andersen MN, Stephens RW, Nielsen HJ, Murphy G, Christensen IJ, Stetler-Stevenson W, Brunner N. High preoperative plasma tissue inhibitor of metalloproteinase-1 levels are associated with short survival of patients with colorectal cancer. Clin Cancer Res 2000;6:4292-4299.

37. Murphy GJ, Nicholson ML. Rapamycin has no effect on fibrosisassociated gene expression or extracellular matrix accumulation when administered to animals with established or early allograft vasculopathy. J Thorac Cardiovasc Surg 2003;126:2058-2064.

38. Mannello F, Gazzanelli G. Tissue inhibitors of metalloproteinases and programmed cell death: conundrums, controversies and potential implications. Apoptosis 2001;6:479-482.

39. Soloway PD, Alexander CM, Werb Z, Jaenisch R. Targeted mutagenesis of Timp-1 reveals that lung tumor invasion is influenced by Timp- 1 genotype of the tumor but not by that of the host. Oncogene 1996;13:2307-2314. 